\title{
Adapting anaerobic consortium to pure and complex lignocellulose substrates at low temperature: kinetics evaluation
}

\author{
Ammar Musbah Saleh Ahmed ${ }^{1} \cdot$ Kovasky Alfonso Buezo ${ }^{1} \cdot$ Noori M. Cata Saady ${ }^{1}$ (D)
}

Received: 15 May 2018 / Accepted: 8 December 2018 / Published online: 15 December 2018

(c) The Author(s) 2018

\begin{abstract}
Purposes The purpose of this research was to evaluate the kinetics of anaerobic microbial culture during adaptation to pure and complex lignocellulosic substrates at low temperature.

Methods Six pairs of $1.0 \mathrm{~L}$ batch reactors maintained at $20^{\circ} \mathrm{C}$ were fed pure (xylan and cellulose) and complex (cow manure and wheat straw) lignocellulosic substrate in three successive cycles of 35 days each. The biogas volume and composition, chemical oxygen demand, and volatile solids were monitored to evaluate the kinetics of the culture during the adaption.

Results Anaerobic culture adapted to digest the pure and complex lignocellulosic substrates at $20{ }^{\circ} \mathrm{C}$ in relatively short period (105 days; 3 successive cycles of 35 days each) in batch reactor studies. The first-order model kinetics revealed that the average increase $\left(\mathrm{day}^{-1} \mathrm{cycle}^{-1}\right)$ in the reaction rate constant over the successive cycles was 0.0831 (xylan) $>0.0235$ (cow manure) $>0.0207$ (wheat straw) $>0.0123$ (xylan:cellulose mixture) $>0.0041$ (cellulose). The rates of the substrate degradation at $20{ }^{\circ} \mathrm{C}$ were: $0.085-0.093$ day $^{-1}$ (cellulose), 0.112-0.278 day $^{-1}$ (xylan), 0.112-0.137 day ${ }^{-1}$ (xylan:cellulose mixture), 0.069-0.116 day ${ }^{-1}$ (cow manure), and 0.057-0.106 day ${ }^{-1}$ (wheat straw).

Conclusions Anaerobic mixed culture can be adapted to pure and complex lignocellulosic substrates and convert them to methane at low temperature $\left(20^{\circ} \mathrm{C}\right)$ in relatively short time (105 days) using a sequential procedure. The culture adaptation to wheat straw proceeded at a slower rate than that for cow manure.
\end{abstract}

Keywords Adaptation $\cdot$ Low temperature $\cdot$ Anaerobic digestion $\cdot$ Lignocellulose $\cdot$ Cow manure $\cdot$ Kinetics

\section{Introduction}

Lignocellulosic agriculture residue and farm waste are abundant biomass of high potential to serve as renewable feedstock for sustainable biogas production and value-added products; however, they are currently undervalued (Paul and Dutta 2018). Anaerobic digestion is a low-cost microbial conversion process (Lynd et al. 2008) which converts biodegradable organic substrates such as manure and farm lignocellulosic waste biomass into methane (Lynd et al. 2008).

Noori M. Cata Saady

nsaady@mun.ca

Ammar Musbah Saleh Ahmed

amsa57@mun.ca

Kovasky Alfonso Buezo

kab310@mun.ca

1 Department of Civil Engineering, Memorial

University of Newfoundland, St. John's,

Newfoundland and Labrador A1B 3X5, Canada
Biogas production through anaerobic digestion of lignocellulose substrates such as cellulose, hemicellulose, cow manure, and wheat straw have been reported in mesophilic and thermophilic processes. However, very little is known about such application at low temperature.

Anaerobic digestion is sensitive to the environmental and operating conditions. Growth conditions such as temperature, $\mathrm{pH}$, type of substrate, reactor design and configuration, mode of operation, and other maintenance procedures impose various selective stresses on microorganisms (Angert et al. 1998; Boivin-Jahns et al. 1995; Ferris et al. 1996). A very small fraction of microorganisms may benefit from these stresses and thus dominate the culture and contribute to its intended functionality. Fastidious microorganisms such as mono-trophic species as well as microorganisms which function in symbiotic interaction with other species will likely be screened out upon the elimination of their substrate or their symbiotic partners, respectively.

Upon exposure to different conditions than the ones prevalent in their indigenous environment, microorganisms 
may adapt by changing their physiological state. Introducing $10 \%$ sucrose in the growth medium of a mixed anaerobic culture maintained on a mixture of acetate and propionate decreased its methanogenic activity by $30-70 \%$ (Dolfing and Bloeman 1985). After 3 months, the methanogenic activity of the culture reflected its growth media composition rather than its original activity before adaptation (Dolfing and Bloeman 1985).

Feeding the culture a single new substrate imposes stress on the various microorganisms and alters their proportions in the reactor. Consequently, the proportion of some trophic groups may increase, decrease, or even disappear. Upon such effects, the culture may transform into a new one. Adapting anaerobic mixed culture on lignocellulosic substrates at low temperature may come at the expenses of fats- and protein-metabolizing microorganisms (Gavala and Lyberatos 2001; Gavala et al. 1999; Guieysse et al. 2001). Precisely, adaptation may induce a population shift from the substrate sensitive to the substrate tolerant microorganisms. Moreover, the kinetics of the culture may change as well. Gavala and Lyberatos (2001) reported that adaptation affected the consumption and kinetics (the maximum specific utilization rate) of various compounds in the mixed anaerobic culture significantly. The adaptation affects the stoichiometry of the reactions which produce the volatile fatty acids during the acidogenesis and acetogenesis (Gavala and Lyberatos 2001).

Temperature is an important factor because it affects both the growth of microbes and the thermodynamics of the bioreactions. The maximum growth rate of microbes increases with temperature. Generally, the growth rates double for each $10{ }^{\circ} \mathrm{C}$ increase in temperature over the range of 10-35 ${ }^{\circ} \mathrm{C}$ (Rittmann and McCarty, 2001). Therefore, upon adaptation to low temperature the culture's growth rate decreases (van Lier et al. 1997). The growth rate of microbes at psychrophilic conditions is less than that at mesophilic conditions.

Methane formation reactions are carried out by two groups of microorganisms: bacteria and archaea (methanogens). Temperature affects the growth and activity of both groups. Lowering the temperature decreases the activity of hydrolytic bacteria thus lowers the rate of hydrolysis. Hydrolysis is generally found to be the rate-limiting step in anaerobic degradation (Dhaked et al. 2010). On the other hand, methanogens are also temperature-dependent (Nozhevnikova et al. 2001). Lowering the temperature may change the dominating metabolic pathway in the microbial culture, particularly methanogens.

To maintain the same methane production output and feedstock loading for anaerobic digestion at low temperatures it is possible to increase the digester volume to provide longer solids retention time (SRT). This accounts for the decreased microbial activity and the slow microbial growth rate. Alternatively, the organic loading rate (OLR) should be decreased.

Thermodynamically, the reaction free energy is a function of the temperature. The free energy of a reaction increases with decreasing temperature. A reaction becomes thermodynamically favorable or feasible when its free energy is negative. Anabolic reactions, which form new cell biomass, have positive free energy. Therefore, they have to be coupled with catabolic reactions (substrate degradation) which have negative free energy so that the overall reaction becomes thermodynamically favorable (von Stockar et al. 2006). Methane formation is growthassociated bioreaction. Although methane production occurs at temperatures near zero (Zeeman et al. 1988) the growth rate is very slow and methane yield is low.

Increasingly, psychrophilic anaerobic digestion is shown to be a promising and an economical process for animal manure and farm residue treatment in clod regions (Gunnigle et al. 2015; Massé et al. 2010; Safley and Westerman 1994). However, the biotechnological potential of psychrophilic anaerobic digestion is underutilized (Kasana and Gulati 2011). Psychrophilic culture could evolve from thermophilic and mesophilic cultures through adaptation and enrichment. Analogously, adaptation and enrichment of mixed anaerobic culture could be used to develop and intensify the lignocellulose (cellulose and hemicellulose) degrading activity in the culture. Although some studies reported biomethane production from lignocellulosic substrates at mesophilic and thermophilic conditions (Adl et al. 2015; Janke et al. 2015; Kang et al. 2014), very few studies (Saady and Massé 2013) have been published on psychrophilic anaerobic digestion of cellulose and hemicellulose. Little is known about the culture kinetics when integrating low temperature with feeding lignocellulose substrate.

Currently, lignocellulose substrates and their by-products such as cellulose and xylan (hemicellulose) are investigated extensively to improve the technologies of their microbial conversion to biogas, bioethanol, biobutanol, etc. Dairy manure is composed of heterogenous undigested or partially digested lignocellulosic biomass. For example, the by-mass percentage of cellulose, hemicellulose, and lignin in dairy manure is $25 \%, 13-20 \%$, and $15 \%$, respectively (Yue et al. 2011). Also, straw such as wheat straw is usually used as a bedding material in livestock farms.

The objective of this study was to assess the adaptation of the anaerobic microbial consortium through the kinetic of biodegradation of lignocellulosic substrates [hemicellulose (xylan), cellulose, xylan:cellulose mixture, cow manure, and wheat straw] and methane production in batch reactors at low temperature $\left(20^{\circ} \mathrm{C}\right)$. 


\section{Materials and methods}

\section{Experimental setup}

The anaerobic digestion experiments were performed in six pairs of $(1.0 \mathrm{~L}$; working volume $=0.5 \mathrm{~L})$ bottles maintained at $20{ }^{\circ} \mathrm{C}$ for three successive cycles to digest (xylan, cellulose, xylan:cellulose mixture, cow manure, and wheat straw). All reactors received $0.5 \mathrm{~L}$ of culture. The reactors were labeled as follows: R0: Control (contained $0.5 \mathrm{~L}$ of culture only; no substrate was added), R1: xylan (fed with $1.24 \mathrm{~g}$ of xylan), R2: cellulose (fed with $0.69 \mathrm{~g}$ cellulose), R3: xylan:cellulose mixture (fed with $0.62 \mathrm{~g}$ xylan and $0.34 \mathrm{~g}$ cellulose; $2: 1$ COD ratio), $\mathrm{R} 4$ : cow manure (fed with $10.26 \mathrm{~g}$ cow manure), and R5: wheat straw (fed with $1.37 \mathrm{~g}$ of shredded wheat straw). The reactors were kept static and were mixed for 1 min once a week just before taking liquid samples. After preparing the reactors and feeding them with the substrates, they were purged with nitrogen $\left(\mathrm{N}_{2}\right)$ gas to establish anaerobic condition. The reactors were then closed with rubber stoppers and sealed with aluminum crimps.

\section{Inoculum and substrates}

The seed inoculum was made up as follows: $2.0 \mathrm{~kg}$ of the culture (30\% total solids) obtained from dry anaerobic digestion reactors $(40 \mathrm{~L})$ was diluted with deionized water, homogenized, and sieved through $250 \mu \mathrm{m}$ sieve to remove large fibers and any floating matter. The mixed liquor passed through the sieve was used as inoculum (TS 0.95\%). For cycle 2 onwards the same culture at the end of the previous digestion cycle was re-used as inoculum for the next cycle. Table 1 gives the total solids (TS), volatile solids (VS), and chemical oxygen demand (COD) of the inoculum. The alkalinity of the dilute culture was $1850 \mathrm{mg} \mathrm{L}^{-1}$ as $\mathrm{CaCO}_{3}$ and was adjusted by adding $5.0 \mathrm{~g}$ of $\mathrm{CaCO}_{3}$ into $8 \mathrm{~L}$ of dilute culture. The final measured alkalinity was $2600 \mathrm{mg} \mathrm{L}^{-1}$ as $\mathrm{CaCO}_{3}$. The dilute culture was incubated for 2 weeks to get rid of any residual substrate. The experiments started when the dilute culture biogas production reached zero.
Pure substrates [cellulose (insoluble fibers of $40 \mu \mathrm{m}$ in particle size) and xylan (insoluble powder from birchwood)] [Sigma Aldrich (Canada)] were used in this study. Bedding-uncontaminated fresh manure from dairy cows was collected, transferred into a plastic container, and stored at $4{ }^{\circ} \mathrm{C}$ until it was fed to the bioreactors. The wheat straw was shredded $(<0.25 \mathrm{~mm})$ and stored at $20{ }^{\circ} \mathrm{C}$ in plastic drum until its use. The substrate's TS, VS, and COD are given in Table 1. The inoculum-to-substrate ratio ranged from 3.1 to 5.6 (Table 1) to ensure fast start-up of the anaerobic digestion depending on results published previously (Chynoweth et al. 1993; Hansen et al. 2004; Hashimoto 1989; Møller et al. 2004).

\section{Biogas measurement}

A calibrated digital gas pressure gauge (Dwyer Model: DPGA-08, Dwyer Instruments Inc., Michigan City, IN, USA) was used to measure the pressure of the biogas produced in the batch bioreactor. The volume of methane production was calculated based on standard temperature and pressure (STP) $(273 \mathrm{~K} ; 1 \mathrm{~atm})$; i.e., normalized liter $\left({ }_{\mathrm{N}} \mathrm{L}\right.$ $\mathrm{CH}_{4}$ ) using Eq. 1.

$V_{\mathrm{CH}_{4 \mathrm{STP}}}=\alpha V_{\mathrm{m}} \frac{T_{\mathrm{s}} \cdot P_{\mathrm{m}}}{T_{\mathrm{m}} \cdot P_{\mathrm{s}}}$,

where $V_{\mathrm{m}}$ is the measured volume of biogas, $\alpha$ is the percentage of $\mathrm{CH}_{4}$ in biogas, $T$ and $P$ which are the actual temperature and atmospheric pressure at the time of measurement, and $T_{\mathrm{s}}$ and $P_{\mathrm{s}}$ are the standard temperature and pressure. $V_{\mathrm{CH}_{4 \mathrm{STP}}}$ is the volume of methane at the standard temperature and atmospheric pressure. The volume of $\mathrm{CH}_{4}$ produced was corrected to that produced in the control reactors. The reported total specific methane yield (SMY) is the cumulative specific $\mathrm{CH}_{4}$ yield which was calculated as the ratio of $\mathrm{CH}_{4}$ produced $\left({ }_{\mathrm{N}} \mathrm{L}\right)$ over the mass of the total VS fed to the bioreactor at the beginning of the experiment. The COD recovery in biogas was calculated as the percentage of $\mathrm{CH}_{4}$ produced relative to the theoretical biochemical methane potential (350 $\left.\mathrm{L} \mathrm{CH}_{4} \mathrm{~kg}^{-1} \mathrm{COD}\right)$.

Table 1 Physicochemical characteristics of the inoculum and substrates

\begin{tabular}{|c|c|c|c|c|c|c|}
\hline & $\begin{array}{l}\text { Inoculum } \\
\text { (control) }\end{array}$ & Xylan & Cellulose & $\begin{array}{l}2: 1 \text { xylan:cellulose } \\
\text { mixture }\end{array}$ & Cow manure ${ }^{\mathrm{a}}$ & Wheat straw \\
\hline Total solids $(\%)$ & 0.97 & 93 & 96 & 95 & 13 & 89 \\
\hline Volatile solids (\%) & 0.73 & 87 & 96 & 90 & 11 & 85 \\
\hline $\operatorname{COD}\left(\mathrm{g} \mathrm{g}^{-1}\right)$ & 0.01 & 1.11 & 1.27 & 1.21 & 1.15 & 1.23 \\
\hline Organic loading rate $\left(\mathrm{g} \mathrm{COD} \mathrm{L}^{-1}\right)$ & NA & 2.75 & 1.73 & 2.24 & 3.04 & 3.36 \\
\hline Inoculum-to-substrate ratio ( $\mathrm{g} \mathrm{VS} \mathrm{g}^{-1} \mathrm{VS}$ ) & NA & 3.4 & 5.6 & 4.2 & 3.1 & 3.1 \\
\hline
\end{tabular}

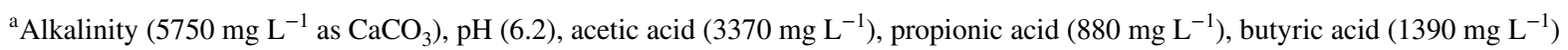




\section{Analytical methods}

\section{Solids and chemical oxygen demand}

Analytical methods used for the physicochemical [total chemical oxygen demand (TCOD), pH, alkalinity, and total and volatile solids (TS and VS, respectively)], biogas composition, and volatile fatty acids (VFAs), elemental analysis, and fiber analysis were according to the Standard Methods (APHA 1992).

Alkalinity was determined according to the method number 2320B Potentiometric titration to preselected $\mathrm{pH}$ 4.38. The TCOD was determined by the closed reflux colorimetric method (APHA 1992). The total solids (TS) and volatile solids (VS) content were determined using method number 2540B for TS and method number 2540E for VS. Briefly, the TS content was determined by drying a $10 \mathrm{~mL}$ sample for $24 \mathrm{~h}$ at $105 \pm 3{ }^{\circ} \mathrm{C}$. The VS content was determined by incinerating the dried solids for $3 \mathrm{~h}$ at $550{ }^{\circ} \mathrm{C}$. The VS content was taken as the weight lost during the incineration; i.e., the VS content was calculated as the difference between the dried solids and fixed solids (ash remained after incineration).

\section{Volatile fatty acids}

The concentrations of individual volatile fatty acids (VFAs) including acetic, propionic, butyric, isobutyric, butyric, valeric and isovaleric acids have been measured according to the method number 5560D. The analysis used a Perkin Elmer gas chromatograph (GC) model 8310 (Perkin Elmer, Waltham, MA, USA) equipped with an autosampler to facilitate the analysis, fitted with FID, and equipped with a J\&W Scientific DB-FFAP high resolution column (30 $\mathrm{m} \times 0.53 \mathrm{~mm} \times 1.00 \mu \mathrm{m}$; Chromatographic Specialties Inc., Ontario) (Saady and Massé 2013, 2015).

Helium, flowing at $9.5 \mathrm{~mL} \mathrm{~min}^{-1}$, was employed as the carrier. The injector temperature was maintained at $200{ }^{\circ} \mathrm{C}$, while the detector temperature was set at $250{ }^{\circ} \mathrm{C}$. A $10 \mathrm{~g}$ of sample was diluted in $20 \mathrm{~mL}$ of deionized water, mixed thoroughly and the liquid part was separated and transferred into a centrifuge tube. After centrifugation for $30 \mathrm{~min}$ at $46,300 \mathrm{~g}, 2 \mathrm{~mL}$ of the supernatant was transferred into $3 \mathrm{~mL}$ centrifuge tube, acidified with phosphoric acid, and centrifuged for $15 \mathrm{~min}$ at $16,300 \mathrm{~g}$. A $0.5 \mathrm{~mL}$ of the supernatant was filtered through a $0.45 \mu \mathrm{m}$ nylon syringe filter into a $1.5 \mathrm{~mL}$ GC tube. The detection limit of acetic acid was $3.5 \mathrm{mg} \mathrm{L}^{-1}$ while the detection limit of all other acids was $1.5 \mathrm{mg} \mathrm{L}^{-1}$. The instrument performance was checked by throwing several standard samples systematically every five unknown samples injection until the end of the analysis of the batch of samples.

\section{Biogas composition}

The content of $\mathrm{CH}_{4}$ and $\mathrm{CO}_{2}$ in biogas were measured weekly using a Hach Carle 400 AGC gas chromatograph (Model 04131-C, Chandler Engineering, Houston, TX, USA) configured for the application 131-C. The application uses a column (1/8 inches) composed of $1.8 \mathrm{~m}$ (805 porapak $\mathrm{N}+205$ Porapak Q), $2.1 \mathrm{~m}$ (80\% molecular sieve $13 \mathrm{X}+20 \%$ molecular Sieve 5A), and $1.8 \mathrm{~m}$ (80\% OV-101 on chromosorb WHP). The column and thermal conductivity detector were operated at $85^{\circ} \mathrm{C}$ with a helium gas flow rate of $30 \mathrm{~mL} \mathrm{~min}^{-1}$. The GC Calibration was performed weekly with a certified gas standard $\left(27.3 \% \mathrm{CO}_{2}, 1.01 \% \mathrm{~N}_{2}, 71.69 \%\right.$ $\left.\mathrm{CH}_{4}, 0.53 \% \mathrm{H}_{2} \mathrm{~S}\right)$. The quantification regression equation has been generated using the same certified gas standards. The linear quantification regression equation covered the range from 0.001 to $100 \%$ (pure gas injection) with an $R^{2}$ value of $0.9991,0.9988$, and 0.9968 for $\mathrm{CH}_{4}, \mathrm{CO}_{2}$, and $\mathrm{H}_{2} \mathrm{~S}$. Additionally and routinely, the GC performance checkup during any gas test was conducted at the beginning, every five injections, and at the end of the analysis of each batch of gas samples. This checkup was conducted by injecting triplicate samples of the certified gas standard at the beginning and injecting one standard gas sample after every five injections of unknown samples until the end of the analysis.

\section{Elemental analysis}

Elemental analysis was conducted on xylan, cellulose, and glucose; the glucose was used as a control to the elemental analysis. Elemental analyses for $\mathrm{CHN}$ and $\mathrm{O}$ were carried out with the Carlo-Erba elemental analyzer, model 1106, according to standard procedure and the results are accurate to $\pm 0.3 \%$. The analysis for carbon $(\mathrm{C})$, hydrogen $(\mathrm{H})$, and nitrogen $(\mathrm{N})$ has been performed based on a modification of the classical (Pella and Colombo 1972). Samples have been weighed accurately to $0.0001 \mathrm{mg}$, tightly enclosed in tin capsules, and analyzed. The analysis for oxygen $(\mathrm{O})$ has been performed based on the Unterzaucher modified method (Pella and Colombo 1973). Samples have been weighed accurately to $0.0001 \mathrm{mg}$, tightly enclosed in silver capsules, and analyzed.

\section{Results and discussion}

\section{Methane production}

The SMY ( ${ }_{\mathrm{N}} \mathrm{L} \mathrm{CH}_{4} \mathrm{~kg}^{-1} \mathrm{VS}$ fed) obtained after 35 days of incubation (corrected to that produced in the control cultures) during the successive cycles are given in Table 2 . The 
Table 2 Specific methane yield for xylan cellulose, cow manure and wheat straw

\begin{tabular}{|c|c|c|c|c|c|}
\hline \multirow[t]{2}{*}{ Reactor } & \multirow[t]{2}{*}{ Substrate } & \multirow[t]{2}{*}{$\begin{array}{l}\text { Theoretical methane } \\
\text { yield }\left({ }_{\mathrm{N}} \mathrm{L} \mathrm{CH}_{4} \mathrm{~kg}^{-1} \mathrm{VS}\right)\end{array}$} & \multicolumn{3}{|c|}{$\begin{array}{l}\text { Maximum specific methane yield }{ }^{\mathrm{a}}\left({ }_{\mathrm{N}} \mathrm{L} \mathrm{CH}_{4}\right. \\
\mathrm{kg}^{-1} \text { VS) }\end{array}$} \\
\hline & & & Cycle 1 & Cycle 2 & Cycle 3 \\
\hline $\mathrm{R} 1$ & Xylan & $394^{\mathrm{b}}$ & $299.2 \pm 8.9$ & $299.7 \pm 4.8$ & $322.5 \pm 2.1$ \\
\hline $\mathrm{R} 2$ & Cellulose & $414.5^{\mathrm{b}}$ & $315.4 \pm 15.5$ & $341.7 \pm 11.3$ & $380.9 \pm 6.7$ \\
\hline R3 & $\begin{array}{l}2: 1 \text { xylan:cellulose } \\
\text { mixture }\end{array}$ & $346.3^{\mathrm{b}}$ & $288.9 \pm 9.9$ & $333.6 \pm 12.9$ & $332.6 \pm 5.9$ \\
\hline $\mathrm{R} 4$ & Cow manure & $469.0^{c}$ & $179.6 \pm 17.7$ & $194.9 \pm 8.8$ & $228.5 \pm 6.3$ \\
\hline R5 & Wheat straw & $214-432^{\mathrm{d}}$ & $192.7 \pm 13.5$ & $211.3 \pm 10.3$ & $246.5 \pm 16.6$ \\
\hline
\end{tabular}

${ }^{\text {a }}$ The yields are corrected for the volume of methane produced by the control culture (no substrate fed)

${ }^{\mathrm{b}}$ Calculated from Buswell and Mueller (1952) (Eqs. 2, 3)

${ }^{\mathrm{c}} \mathrm{M} \varnothing$ ller et al. (2004)

${ }^{\mathrm{d}}$ Bauer et al. (2009) and Møller et al. (2004), respectively
Table 3 Average of the percentage of theoretical methane yield recovery during the successive cycles

\begin{tabular}{llll}
\hline Reactor & \multicolumn{3}{l}{ Percent theoretical methane yield recovery } \\
\cline { 2 - 4 } & Cycle 1 & Cycle 2 & Cycle 3 \\
\hline R1 & $75.9 \pm 2.3$ & $76.1 \pm 1.2$ & $81.9 \pm 0.5$ \\
R2 & $76.1 \pm 3.7$ & $82.4 \pm 2.7$ & $91.9 \pm 1.6$ \\
R3 & $81.7 \pm 2.9$ & $96.3 \pm 3.7$ & $96.0 \pm 1.7$ \\
R4 & $38.3 \pm 3.7$ & $41.6 \pm 1.8$ & $48.7 \pm 1.3$ \\
R5 & $44.6 \pm 3.1$ & $48.9 \pm 2.4$ & $57.1 \pm 3.8$ \\
\hline
\end{tabular}

elemental analysis revealed that the molecular formulae for cellulose and xylan are $\mathrm{C}_{5.928} \mathrm{H}_{10} \mathrm{O}_{4.965}$ and $\mathrm{C}_{5.148} \mathrm{H}_{8} \mathrm{O}_{4.418}$, respectively.

The theoretical methane yields for cellulose and xylan were calculated using the results of the elemental analysis and Buswell and Mueller's Eqs. (2, 3) (Buswell and Mueller 1952). Table 3 gives the percentage of the theoretical methane yield recovered in the successive cycles in the cultures fed pure and complex substrates. The cultures fed with the pure substrate (xylan, cellulose, xylan:cellulose mixture) recovered between 82 and $96 \%$ of the theoretical methane yield in cycle 3 compared to between 76 and $82 \%$ in cycle 1 .

The highest percentage of theoretical methane yield recovery $(96.0 \%)$ was in the culture fed a mixture of xylan:cellulose mixture whereas the lowest percentage $(48.7 \%$ ) was in the culture fed with cow manure:
The rate kinetic and the extent of substrate biodegradability can be obtained from methane production curve pattern during the batch anaerobic digestion. The SMY profiles in the successive cycles of anaerobic digestion of pure and complex substrates in R1-R5 at low temperature $\left(20^{\circ} \mathrm{C}\right)$ are given in Fig. 1a-e. Generally, for all substrates and during all successive cycles the anaerobic digestion proceeded well without any observable inhibition. The $\mathrm{CH}_{4}$ production profiles are composed of two phases: phase I which exhibited linear kinetics where the $\mathrm{CH}_{4}$ production increases linearly with time and phase II in which the $\mathrm{CH}_{4}$ production decreased towards a plateau. Nevertheless, some variations in the $\mathrm{CH}_{4}$ profiles during the successive cycles can be noticed as well.

The rate of substrate degradation can be correlated to the $\mathrm{CH}_{4}$ production rate since the latter can be calculated from the $\mathrm{CH}_{4}$ production profiles. During the first cycle, the culture started degrading all substrates-fed immediately at a relatively high rate. Notice that the duration of this phase varied for the different substrates particularly during cycle 1 ; it was longer for the cultures fed pure substrate or their mixture ( $>10$ days) than that for the cultures fed complex substrates (cow manure and wheat straw) (6-7 days). In addition, the rates of $\mathrm{CH}_{4}$ production in cultures fed with the pure substrates were faster than those of complex substrates (Table 4).

For comparison and taking R5 (wheat straw) as a reference, the rate of methane production for R1 (xylan) was

$$
\begin{aligned}
\mathrm{C}_{c} \mathrm{H}_{h} \mathrm{O}_{o} \mathrm{~N}_{n} \mathrm{~S}_{s}+\left(c-\frac{h}{4}-\frac{o}{2}+\right. & \left.\frac{3 n}{4}+\frac{s}{2}\right) \mathrm{H}_{2} \mathrm{O} \rightarrow\left(\frac{c}{2}+\frac{h}{8}-\frac{o}{4}-\frac{3 n}{8}-\frac{s}{4}\right) \mathrm{CH}_{4} \\
& +\left(\frac{c}{2}-\frac{h}{8}+\frac{o}{4}+\frac{3 n}{8}+\frac{s}{4}\right) \mathrm{CO}_{2}+n \mathrm{NH}_{3}+s \mathrm{H}_{2} \mathrm{~S}
\end{aligned}
$$

$B_{\text {theoretical }}=\frac{\left(\frac{c}{2}+\frac{h}{8}-\frac{o}{4}-\frac{3 n}{8}-\frac{s}{4}\right) \cdot 22.4}{12 c+h+16 o+14 n+32 s}=\frac{\mathrm{LCH}_{4}}{g \mathrm{VS}}$.
1.3-1.6 times that of R5, and for R2 (cellulose) it was 1.5-1.6 times that of R5. Similarly, R3 (fed mixture of the pure substrates) produced methane at a rate of $1.3-1.6$ of that 

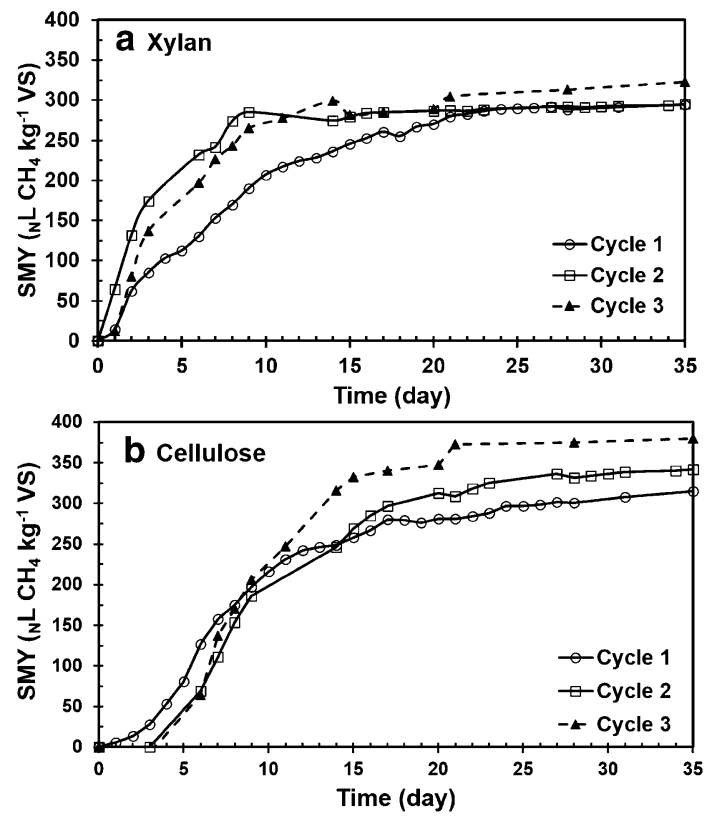

Table 4 Average of the $\mathrm{CH}_{4}$ production rate during the successive cycles

\begin{tabular}{llll}
\hline Reactor & \multicolumn{3}{l}{$\begin{array}{l}\text { Maximum } \mathrm{CH}_{4} \text { production rate }\left({ }_{\mathrm{N}} \mathrm{CH}_{4} \mathrm{~kg}^{-1} \mathrm{VS}\right. \\
\text { day }\end{array}$} \\
\cline { 2 - 4 } & Cycle 1 & Cycle 2 & Cycle 3 \\
\hline R1 & $8.549 \pm 0.254$ & $8.563 \pm 0.137$ & $9.214 \pm 0.014$ \\
R2 & $9.011 \pm 0.443$ & $9.763 \pm 0.323$ & $10.88 \pm 0.191$ \\
R3 & $8.083 \pm 0.283$ & $9.531 \pm 0.369$ & $9.503 \pm 0.169$ \\
R4 & $5.131 \pm 0.506$ & $5.569 \pm 0.251$ & $6.529 \pm 0.180$ \\
R5 & $5.506 \pm 0.386$ & $6.037 \pm 0.294$ & $7.043 \pm 0.474$ \\
\hline
\end{tabular}

produced by R5. Notice that the rate of methane production in R4 (cow manure) was almost $90 \%$ of that calculated for R5.

Generally, the specific methane yield (SMY) and its rate of production increased successively from cycle 1 to 2 and then to cycle 3 in all reactors except for R3 (fed with pure substrate mixture) which exhibited marginal decrease $(0.2 \%)$ in cycle 3 . The SMY increased by $7.6 \%$ from cycle 2 to 3 for R1, and increased by $4.5 \%$ and $9.7 \%$ for cycle 2 and 3, respectively, in R2 (fed with cellulose). Although the SMY increased by $17.9 \%$ from cycle 1 to 2 in R3 no further increase was measured in cycle 3 . The cultures fed complex substrate exhibited a successive increase in the SMY. The increase was $8.5 \%$ and $17.2 \%$ in cycle 2 and cycle 3, respectively, in R4 (fed with cow manure). Similarly, the increase in specific methane yield was 9.75 and $16.7 \%$, respectively, in R5. It is worthwhile to notice that the percentage of increase in the SMY in pure substrates-fed culture was less than the corresponding increase in SMY in the culture fed with a complex substrate. This is likely due to the nature of the substrate. Cow feces contains carbohydrates, proteins, and fats which require varying degradation times; therefore, they could have contributed to the increase in the SMY observed during cycle 2 and 3. Wheat straw, on the other hand, is slowly degraded substrate (Pohl et al. 2013); thus, the observed increase in SMY could have been from the residual of the substrate from the previous two cycles. However, the $\mathrm{CH}_{4}$ production profiles changed significantly in cycle 2 and 3 . In R1, the rate of methane production increased during the exponential phase in the order cycle $3>$ cycle $2>$ cycle 1 and this phase lasted longer compared to that in cycle 1 (Fig. 1a). Notice that $90 \%$ of the maximum SMY obtained in R1 has been achieved in 12 days during cycle 3 compared to 20 days in cycle 1 and 14 days in cycle 2 . This indicates an increase in the activity of the xylan degrading microorganisms from cycle 1 to 3 .

Notice that $90 \%$ of the maximum SMY in R2 has been

Fig. 1 Profile of specific methane yield (SMY) during the first 35 days of the anaerobic digestion at $20{ }^{\circ} \mathrm{C}$ in successive cycles (values shown are average of duplicate bioreactors) achieved in 17 days during cycle 3 compared to 22 days in cycle 1 and 19 days in cycle 2 . The R2 experienced a lag phase in methane production of 2 days in cycle 1 
and 4 days in cycle 2 and 3 . The lag phase is the time needed by the microorganisms to acclimatize to a new environment (Echiegu 2015) and substrates. Generally, the physiological processes by which microorganisms adapt to the new environment or substrates dictates the length of the lag phase (Rolfe et al. 2012). Non-fiber carbohydrates have been found easily accessible to microbial degradation (Janke et al. 2015) with short lag phase whereas substrates with increased fiber content such as the cellulose fed to R2 were reported to exhibits increased lag phase (Nielfa et al. 2015). Moreover, the duration of the lag phase is also related to the initial buffer capacity of the fermentation liquor (Mao et al. 2015). The alkalinity of the mixed liquor was not adjusted at the beginning of the cycle 2 and 3. Additionally, by the end of cycle 1 the content of the undegraded more recalcitrant organics which remained in the reactor after fermentation increased and might have lengthened the lag phases to 4 days in cycle 2 and 3 compared to 2 days in cycle 1 ; similar observation has been reported previously by Wilkie et al. (2000).

In the culture fed mixture of pure substrates (R3), the exponential phase of methane production lasted longer in cycle 3 (14 days) and cycle 2 ( 8 days) compared to cycle 1 (3 days). Notice that $90 \%$ of the maximum SMY in R3 has been achieved in 14 days during cycle 3 compared to 20 and 17 days in cycle 1 and 2, respectively. This represents $70-82 \%$ increase in the activity of the microorganisms degrading the xylan:cellulose mixture in cycle 2 and 3 , respectively.

The culture in R4 (fed cow manure) exhibited a steady increase in the SMY of $8.5 \%$ and $17.2 \%$ in cycle 2 and cycle 3 , respectively. The specific methane production rate was generally lower than that measured in cultures fed with other substrates. Interestingly, the exponential phase of the methane production profile lasted longer in cycle 3 ( 9 days) compared to cycle 1 and 2 (6 days). Around $90 \%$ of the maximum SMY in R4 has been achieved in 22 days during cycle 3 compared to 27 and 25 days in cycle 1 and 2 , respectively. The increase in the duration of the exponential phase of methane production and the faster recovery of the $90 \%$ of the maximum SMY with the increase in cycle number indicates an enhancement in the activity of the microorganisms. This could be due to increase in the amount of the viable/ active cells or the production of more active cold-adapted enzymes with high specific activities at low temperatures (high turn over rates) (Casanueva et al. 2010). For R5 (fed wheat straw) no change could be observed in the methane production rate and the duration of the exponential phase of methane production among the four successive cycles. About $90 \%$ of the maximum SMY from wheat straw has been achieved in 27, 22, and 22 days in cycles 1, 2, and 3, respectively. It seems that the culture adapted relatively at the same pace to both complex substrates.
In terms of COD recovery in methane, Table 5 gives the calculated percentages for the successive cycles in the cultures fed with the various substrate examined.

The difference between the percentage of COD recovery in methane and the percentage of the theoretical methane yield recovery is likely because the microorganisms used some of the substrate for growth and maintenance. The theoretical methane yield calculated from Eq. 3 is not corrected for biomass growth since Eq. 2 assumes that all the substrate will be converted into gaseous by-products. The microorganisms utilize about $5-10 \%$ of the substrate for growth (Rittmann and McCarty 2001). Generally, the COD recovery in all the cultures fed pure or complex substrates increased in cycle 2 whereas in cycle 3 the increase was marginal (1-2\%). For example, in R2, the COD recovered as methane by day 15 was higher (72.4\%) for cycle 2 and (73.3\%) for cycle 3 compared to $55.9 \%$ in cycle 1 . This might indicate that the culture needed a relatively short time (two successive cycles, i.e., 70 days) to adapt to the new substrates.

\section{Modeling kinetics of methane production}

The activity of the microorganisms catalyzing the $\mathrm{CH}_{4}$ production during anaerobic digestion depends on the substrate, environmental conditions (temperature and $\mathrm{pH}$ ), and physiological characteristics of the cell (Rolfe et al. 2012). The fiber content and its quality vary among the various pure and mixed substrates used in this study (Table 1). Kinetic model can elucidate the changes in the kinetics of the microbial cultures due to adaptation. The model would describe the $\mathrm{CH}_{4}$ production curves obtained from the anaerobic digestion of the pure and complex fibrous substrates during successive cycles conducted under the same condition. Moreover, the model can provide information useful for predicting the digestion of fiber in animal manure and lignocellulosic biomass based on pure substrates studies. Fitting $\mathrm{CH}_{4}$ production data to a mathematical model to describe the progress of methane production and estimate the kinetics parameters allows comparing the effects of various substrates and detect if any adaptation took place.

Table 5 Average of percent COD recovery as methane during the successive cycles

\begin{tabular}{llll}
\hline Reactor & \multicolumn{3}{l}{ Percent COD recovery in $\mathrm{CH}_{4}$ at day 15} \\
\cline { 2 - 4 } & Cycle 1 & Cycle 2 & Cycle 3 \\
\hline R1 & $55.8 \pm 0.7$ & $67.6 \pm 0.5$ & $69.1 \pm 0.8$ \\
R2 & $55.9 \pm 5.3$ & $72.4 \pm 0.5$ & $73.3 \pm 1.4$ \\
R3 & $51.8 \pm 5.9$ & $66.9 \pm 11$ & $67.2 \pm 1.3$ \\
R4 & $29.3 \pm 2.3$ & $49.0 \pm 1.0$ & $52.9 \pm 3.9$ \\
R5 & $31.1 \pm 3.0$ & $45.5 \pm 2.1$ & $46.5 \pm 2$. \\
\hline
\end{tabular}


The model was developed to describe the methane generation in the batch bioreactors of volume $(V)$ using mass balance approach (Eq. 4) (Rittmann and McCarty 2001) and through monitoring COD concentration $(C)$ through $\mathrm{CH}_{4}$ production:

$V \frac{\mathrm{d} C}{\mathrm{~d} t}=Q_{\mathrm{o}} C_{\mathrm{o}}-Q_{\mathrm{o}} C+\operatorname{Vr} C$

where $Q_{\mathrm{o}}$ is the input flow to the bioreactor; $C_{\mathrm{o}}$ is the concentration of COD fed to the reactor, and $C$ is the concentration of COD at any time, and $r$ is the reaction rate of methane. Since for batch bioreactor $Q_{\mathrm{o}}=0$; the Eq. 4 becomes:

$V \frac{\mathrm{d} C}{\mathrm{~d} t}=\operatorname{Vr} C$

For the first-order rate kinetic model, the time rate of change in the concentration of COD in a bioreactor is a function of the concentration $(C)$ and the rate constant $(k)$ :

$\frac{\mathrm{d} C}{\mathrm{~d} t}=-k C$

Solving this differential equation by integration yields:

$\ln \frac{C_{\mathrm{o}}}{C}=k t$

Although Eq. 7 uses the substrate's concentration (COD) it could be modified to give the methane yield through developing a correlation between a substrate (COD) biodegradability and methane yield at any time $(Y)$. To achieve this, it is assumed that all substrate consumed is to be converted into biogas; this introduces a marginal error because methane production is a growth-associated reaction; therefore, some substrate (COD) will be consumed for growth and production of new cell biomass. Equation 7 can now be written in terms of methane yield as follows:

$Y=Y_{\max }\left(1-\operatorname{Exp}^{-k t}\right)$,

where $Y$ is methane volume $\left({ }_{\mathrm{N}} \mathrm{L}\right)$ produced at time $t$ (day), $Y_{\max }$ is maximum methane volume $\left({ }_{\mathrm{N}} \mathrm{L}\right)$ produced, $k$ is the reaction rate constant $\left(\right.$ day $\left.^{-1}\right)$, and $t$ is incubation time (day). Now it is possible to estimate the reaction rate constant $(k)$ of the $\mathrm{CH}_{4}$ production reaction by fitting the data of $\mathrm{CH}_{4}$ production with time to the kinetic model (Eq. 7).

The nonlinear regression was performed using nonlinear regression function of POLYMATH software version 6.1 (Willimantic, CT, USA) with the objective of minimum sum of squared difference (SSR) between experimentally observed and model-estimated values of methane yield. The substrates examined in this study showed identical patterns of reaction progress with time. The values of the reaction rate constant $(k)$ are given in Table 6.
Table 6 The reaction rate constant and the regression coefficient for the successive cycles

\begin{tabular}{llll}
\hline Reactor & Cycle 1 & Cycle 2 & Cycle 3 \\
\hline R1 & $0.1116^{\mathrm{a}}\left(0.9935^{\mathrm{b}}\right)$ & $0.1489(0.9768)$ & $0.2778(0.9907)$ \\
R2 & $0.0851(0.9440)$ & $0.0862(0.9132)$ & $0.0932(0.9935)$ \\
R3 & $0.1118(0.9671)$ & $0.1159(0.9898)$ & $0.1365(0.9696)$ \\
R4 & $0.0688(0.9900)$ & $0.0698(0.9890)$ & $0.1159(0.9790)$ \\
R5 & $0.0565(0.9800)$ & $0.0817(0.9910)$ & $0.1056(0.9830)$ \\
\hline
\end{tabular}

${ }^{\mathrm{a}}$ The reaction rate constant $(k)$ in $\mathrm{day}^{-1}$

${ }^{\mathrm{b}}$ The regression coefficient $\left(R^{2}\right)$

Since the rate of $\mathrm{CH}_{4}$ production is proportional to the rate of the substrate degradation with time then the greater the value of the reaction rate constant $(k)$ the faster the degradation of the substrates. The ranking of the first-order reaction rate constant $(\mathrm{k})$ in the three successive cycles were as follows: Cycle 1: R3 $>$ R1 $>$ R2 $>$ R4 $>$ R5; Cycle 2: $\mathrm{R} 1>\mathrm{R} 3>\mathrm{R} 2>\mathrm{R} 5>\mathrm{R} 4$; Cycle 3: R1 $>\mathrm{R} 3>\mathrm{R} 2>\mathrm{R} 4>\mathrm{R} 5$. Obviously, the kinetics differentiated between the two categories of substrates (pure and complex). The model provided a numerical indicator ( $k$ value) (Table 6) that wheat straw $\left(k=0.0565\right.$ day $\left.^{-1}\right)$ was the less degradable substrate among those tested in cycle 1 and that cow manure $(k=0.0688$ day $^{-1}$ ) was the second less degradable substrate while the pure substrates, xylan, xylan:cellulose mixture, and cellulose, showed the same degradability $(k=0.1116,0.1118$, and $0.0932 \mathrm{day}^{-1}$, respectively). Although the reaction rate constant for R1 degradation increased by $104 \%$ (from cycle 1 to cycle 3 upon adaptation) the corresponding reaction rate constant for R2 degradation increased by only $9.5 \%$. Notice that addition of cellulose to xylan at a ratio (1:2 by COD) decreased the percentage of increase in the reaction rate constant of this mixture degradation to only $22.1 \%$ compared to $104 \%$ in R1. This might indicate that the culture did not contain high active cellulolytic microorganisms or their adaptation might need longer time.

Upon adaptation the reaction rate constant calculated for R5 degradation increased by $86.9 \%$, i.e., from 0.0565 day $^{-1}$ (cycle 1) to 0.1056 day $^{-1}$ (cycle 3 ). Similarly, adaptation increased the reaction rate constant in $\mathrm{R} 4$ by $68.5 \%$, i.e., from $0.0688 \mathrm{day}^{-1}$ (cycle 1) to $0.1159 \mathrm{day}^{-1}$ (cycle 3).

Variation in the $k$ value determined by the model for the successive cycles is shown in Fig. 2. All cultures fed pure and complex substrates showed increasing trends in the $k$ value, but to various extents. The ranking of the increase in $k$ value with adaptation was $0.0831(\mathrm{R} 1)>0.0235$ $(\mathrm{R} 4)>0.0207(\mathrm{R} 5)>0.0123(\mathrm{R} 3)>0.0041(\mathrm{R} 2)$.

The differences in the reaction rate constants of the $\mathrm{CH}_{4}$ production among $\mathrm{R} 1, \mathrm{R} 2$, and $\mathrm{R} 5$ reflect the effects of the physicochemical characteristics of the substrate on the adaptation of the microbial consortium. The pure substrates are 


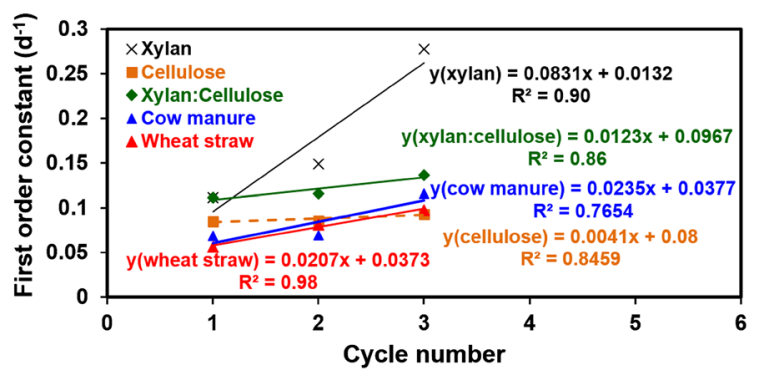

Fig. 2 Variation of the kinetic (reaction rate constant) during the successive cycles of anaerobic digestion

readily degradable, but when they are part of a complex structure of lignocellulosic material such as wheat straw they become less degradable. It must be noted that wheat straw contained $(7.3 \%)$ by-mass lignin whereas xylan and cellulose were pure substrates (lignin free). This explains the difference in the amount of increment in the $k$ value observed in R1 and R3 compared to that observed in R4 and R5. Similarly, cow manure contains fibers composed of cellulose (23.61\%), hemicellulose (18.71\%) and lignin (11.3\%). It must be taken into account that most of the readily digestible cellulose and hemicellulose in the cow diet have been digested in the animal digestive system and what is left of fiber in the cow manure is the part which is protected by the lignin. This explains why the increase in the $k$ value in $\mathrm{R} 4$ (0.0235) during the successive cycles of anaerobic digestion at $20^{\circ} \mathrm{C}$ was lower than that estimated for R1 (0.0831). However, the increase in $k$ value in $\mathrm{R} 4$ (0.0235) over the successive cycles is greater than that in R5 (0.0207) (Fig. 2) might be due to the fats and proteins contained in the cow manure. Wheat straw does not contain any fats, and its content of protein is minimum.

The applicability of a first-order model depends to a large extent on the characteristics and quality of inoculums and that some of the variability in the kinetic constants in models is dictated by the inoculum (Neves et al. 2008). The kinetic of $\mathrm{CH}_{4}$ production from fiber digestion has previously been modeled as a first-order reaction (Kang et al. 2014; Adl et al. 2015; Castano 2012). However, the comparison of the results from this study with values of the reaction rate constant reported in literature should be conducted cautiously because some studies report the first-order kinetic of the hydrolysis step rather than the entire methane production process. The values of $k$ cited from the literature in Table 7 are for the whole anaerobic digestion process unless indicated otherwise. The rate estimated for cellulose $\left(0.085-0.093 \mathrm{day}^{-1}\right)$ in this study is a mid-way between the lower and the upper limits of those reported by other studies $\left(0.05-0.18\right.$ day $\left.^{-1}\right)$ (Table 7). This might be due to the effect of the lower temperature $\left(20^{\circ} \mathrm{C}\right)$ compared to that of mesophilic $\left(28-35^{\circ} \mathrm{C}\right)$ for the studies cited. Notice that the rate estimated for cellulose degradation in this study forms about $41-48 \%$ of that reported by Desvaux et al. (2001) for cellulose digestion by a pure culture of Clostridium cellulolyticum which always follows first-order kinetics with $k$ value $\left(0.192\right.$ day $\left.^{-1}\right)$.

The $k$ value obtained in this study for xylan $(0.112-0.278$ day $^{-1}$ ) is within the values reported previously for carbohydrate $\left(0.120-0.320 \mathrm{day}^{-1}\right)$ (Neves et al. 2008). The $k$ value estimated for cow manure (0.069-0.116 day $\left.{ }^{-1}\right)$ compares well with $0.063 \mathrm{day}^{-1}$ reported by Castano (2012) for anaerobic digestion of dairy manure at $20^{\circ} \mathrm{C}$. Additionally, it compares well with the $0.07-0.08$ day $^{-1}$ reported by Kang et al. (2014) for digesting dairy manure at $35^{\circ} \mathrm{C}$. Nevertheless, it is generally within the value $\left(0.08 \mathrm{day}^{-1}\right)$ reported by Hobson (1983) for slowly degradable cow slurry. Although the impact of temperature is obvious the culture adapted well to the new substrate at $20^{\circ} \mathrm{C}$.

\section{Conclusions}

Anaerobic culture adapted to digest cellulose, xylan, cellulose and xylan mixture, cow manure, and wheat straw at low temperature $\left(20^{\circ} \mathrm{C}\right)$ in relatively short period $(3$ successive cycles of 35 days each). First-order model kinetic revealed that the increase in the reaction rate over the successive cycles was 0.0831 (xylan) $>0.0124$ (xylan:cellulose) $>0.0113$ (wheat straw) $>0.0077$ (cow manure) $>0.0041$ (cellulose). The rate of the substrate degradation at $20{ }^{\circ} \mathrm{C}$ were: $0.085-0.093$ day $^{-1}$ (cellulose), 0.112-0.278 day ${ }^{-1}$ (xylan), 0.112-0.137 $\mathrm{day}^{-1}$ (xylan:cellulose mixture), 0.069-0.116 day ${ }^{-1}$ (cow manure), and $0.057-0.106 \mathrm{day}^{-1}$ (wheat straw). The physicochemical characteristics of the substrates affect the adaptation of the microbial consortium and lead to differences in the reaction rate constants of the $\mathrm{CH}_{4}$ production. Adding cellulose to hemicellulose decreased the percentage of increase in the reaction rate constant during adaptation compared to hemicellulose only. Unless high active cellulolytic microorganisms present in the culture its adaptation might need longer time. 
Table 7 The first-order reaction rate constants of methane production for lignocellulosic substrate

\begin{tabular}{|c|c|c|c|}
\hline Substrate & $\begin{array}{l}\text { Tempera- } \\
\text { ture }\left({ }^{\circ} \mathrm{C}\right)\end{array}$ & $\begin{array}{l}\text { The reaction rate } \\
\text { constant } k\left(\text { day }^{-1}\right)\end{array}$ & References \\
\hline Cellulose & 20 & $0.085-0.093$ & This study \\
\hline Xylan & 20 & $0.112-0.278$ & This study \\
\hline Cellulose-xylan mixture & 20 & $0.112-0.137$ & This study \\
\hline Cow manure & 20 & $0.069-0.116$ & This study \\
\hline Wheat straw & 20 & $0.057-0.106$ & This study \\
\hline Cellulose & NR & 0.180 & Gunaseelan (2009) \\
\hline Cellulose (in cattle manure) & 30 & 0.05 & Singh et al. (1982) \\
\hline Cellulose & 28 & 0.17 & Heukelekian (1927) \\
\hline Cellulose & 35 & 0.12 & Greco et al. (1983) \\
\hline Cellulose & NR & $0.192^{\mathrm{a}}$ & Desvaux et al. (2001) \\
\hline Avicel cellulose & NR & 0.14 & Chynoweth et al. (2001) \\
\hline Excess cellulose food waste & 35 & 0.18 & Qamaruz-Zaman and Milke (2012) \\
\hline $\begin{array}{l}\text { Restaurant waste with excess } \\
\text { Carbohydrates }\end{array}$ & 37 & 0.120 & Neves et al. (2008) \\
\hline Carbohydrates & 37 & 0.320 & Neves et al. (2008) \\
\hline Pig manure and straw & 35 & 0.02 & Llabrés-Luengo and Mata-Alvarez (1987) \\
\hline Pig manure & 38 & & Adl et al. (2015) \\
\hline Hydrolysis & & 0.105 & \\
\hline Acidogenesis & & 0.106 & \\
\hline Methanogenesis & & 0.231 & \\
\hline Cow manure slurry & 35 & 0.09 & Karim et al. (2007) \\
\hline \multirow[t]{3}{*}{ Dairy manure } & 25 & $0.105-0.114$ & Castano (2012) \\
\hline & 20 & $0.049-0.063$ & \\
\hline & 15 & $0.044-0.047$ & \\
\hline Dairy manure & 35 & $0.07-0.08$ & Kang et al. (2014) \\
\hline Cow slurry & & & Hobson (1983) \\
\hline Slowly degradable & & 0.08 & \\
\hline Rapidly degradable & & 0.32 & \\
\hline Dairy manure & 38 & & Adl et al. (2015) \\
\hline Hydrolysis & & 0.093 & \\
\hline Acidogenesis & & 0.143 & \\
\hline Methanogenesis & & 0.146 & \\
\hline Bedding straw & 35 & $0.008-0.010$ & Torres-Castillo et al. (1995) \\
\hline Rice straw & 38 & & Adl et al. (2015) \\
\hline Hydrolysis & & 0.093 & \\
\hline Acidogenesis & & 0.920 & \\
\hline Methanogenesis & & 1.350 & \\
\hline Sugarcane straw & 38 & $0.075-0.102$ & Janke et al. (2015) \\
\hline
\end{tabular}

${ }^{\mathrm{a}}$ By pure culture of Clostridium cellulolyticum
Acknowledgements This research was partially supported by the Seed, Bridge and Multidisciplinary Fund (2018) from the Memorial University of Newfoundland.

Open Access This article is distributed under the terms of the Creative Commons Attribution 4.0 International License (http://creativeco mmons.org/licenses/by/4.0/), which permits unrestricted use, distribution, and reproduction in any medium, provided you give appropriate credit to the original author(s) and the source, provide a link to the Creative Commons license, and indicate if changes were made.

\section{References}

Adl M, Sheng K, Gharibi A (2015) Examining a pretty simple and low cost method for modeling of biogas production from biodegradable solids. Energy Proc 75:748-753. https://doi.org/10.1016/j. egypro.2015.07.504

Angert ER, Northup DE, Reysenbach A-L, Peek AS, Goebel BM, Pace NR (1998) Molecular phylogenetic analysis of a bacterial community in Sulphur River, Parker Cave, Kentucky. Am Mineralogist 83:1583-1592. https://doi.org/10.2138/am-1998-11-1246 
APHA (1992) Standard methods for the examination of water and wastewater. American Public Health Association, Washington, D.C.

Bauer A, Bösch P, Friedl A, Amon T (2009) Analysis of methane potentials of steam-exploded wheat straw and estimation of energy yields of combined ethanol and methane production. J Biotechnol 142:50-55. https://doi.org/10.1016/j.jbiotec.2009.01.017

Boivin-Jahns V, Bianchi A, Ruimy R, Garcin J, Daumas S, Christen R (1995) Comparison of phenotypical and molecular methods for the identification of bacterial strains isolated form a deep subsurface environment. Appl Environ Microbiol 61:3400-3406

Buswell AM, Mueller HF (1952) Mechanism of methane fermentation. Ind Eng Chem 44:550-552. https://doi.org/10.1021/ie50507a033

Casanueva A, Tuffin M, Cary G, Cowan DA (2010) Molecular adaptations to psychrophily: the impact of 'omic' technologies. Trends Microbiol 18:374-381. https://doi.org/10.1016/j.tim.2010.05.002

Castano JM (2012) Anaerobic digestion of low rate digesters in temperate climates. PhD Dissertation. The Ohio State University

Chynoweth DP, Turick CE, Owens JM, Jerger DE, Peck MW (1993) Biochemical methane potential of biomass and waste feedstocks. Biomass Bioenerg 5:95-111. https://doi.org/10.1016/09619534(93)90010-2

Chynoweth DP, Owens JM, Legrand R (2001) Renewable methane from anaerobic digestion of biomass. Renew Energy 22:1-8. https ://doi.org/10.1016/s0960-1481(00)00019-7

Desvaux M, Guedon E, Petitdemange H (2001) Kinetics and metabolism of cellulose degradation at high substrate concentrations in steady-state continuous cultures of Clostridium cellulolyticum on a chemically defined medium. Appl Environ Microbiol 67:38373845. https://doi.org/10.1128/aem.67.9.3837-3845.2001

Dhaked RK, Singh P, Singh L (2010) Biomethanation under psychrophilic conditions. Waste Manag 30:2490-2496. https://doi. org/10.1016/j.wasman.2010.07.015

Dolfing J, Bloeman WGBM (1985) Activity measurements as a tool to characterize the microbial composition of methanogenic environments. J Microbiol Methods 4:1-12. https://doi.org/10.1016/01677012(85)90002-8

Echiegu EA (2015) Kinetic models for anaerobic fermentation processes-a review. Am J Biochem Biotechnol 11(3):132-148. https ://doi.org/10.3844/ajbbsp.2015.132.148

Ferris MJ, Ruff-Roberts AL, Kopczynski ED, Bateson MM, Ward DM (1996) Enrichment culture and microscopy conceal diverse thermophilic Synechococcus populations in a single hot spring microbial mat habitat. Appl Environ Microbiol 62:1045-1050

Gavala HN, Lyberatos G (2001) Influence of anaerobic culture acclimation on the degradation kinetics of various substrates. Biotechnol Bioeng 74:181-195

Gavala HN, Skiadas IV, Lyberatos G (1999) On the performance of a centralised digestion facility receiving seasonal agroindustrial wastewaters. Water Sci Technol 40:339-346. https://doi. org/10.1016/S0273-1223(99)00382-0

Greco RL, Coto JM, Dentel SK, and Gossett JM (1983) Aluminumorganic influencing anaerobic digestion of coagulated substrates, Technical Rep. Environmental Engineering Department, Cornell University, Ithaca

Guieysse B, Wikström P, Forsman M, Mattiasson B (2001) Biomonitoring of continuous microbial community adaptation towards more efficient phenol-degradation in a fed-batch bioreactor. Appl Microbiol Biotechnol 56:780-787. https://doi.org/10.1007/s0025 30100676

Gunaseelan VN (2009) Biomass estimates, characteristics, biochemical methane potential, kinetics and energy flow from Jatropha curcus on dry lands. Biomass Bioenerg 33:589-596. https://doi. org/10.1016/j.biombioe.2008.09.002

Gunnigle E, Nielsen JL, Fuszard M, Botting CH, Sheahan J, Vincent $\mathrm{O}$ et al (2015) Functional responses and adaptation of mesophilic microbial communities to psychrophilic anaerobic digestion. FEMS Microbiol Ecol 91(12):fiv132. https://doi.org/10.1093/ femsec/fiv 132

Hansen TL, Schmidt JE, Angelidaki I, Marca E, la C Jansen J, Mosbæk $\mathrm{H}$ et al (2004) Method for determination of methane potentials of solid organic waste. Waste Manag 24:393-400. https://doi. org/10.1016/j.wasman.2003.09.009

Hashimoto AG (1989) Effect of inoculum/substrate ratio on methane yield and production rate from straw. Biol Wastes 28:247-255. https://doi.org/10.1016/0269-7483(89)90108-0

Heukelekian H (1927) Decomposition of cellulose in fresh sewage solids. Ind Eng Chem 19:928-930. https://doi.org/10.1021/ie502 $12 \mathrm{a} 026$

Hobson PN (1983) The kinetics of anaerobic digestion of farm wastes. J Chem Technol Biotechnol 33:1-20. https://doi.org/10.1002/ jctb. 280330102

Janke L, Leite A, Nikolausz M, Schmidt T, Liebetrau J, Nelles M (2015) Biogas production from sugarcane waste: assessment on kinetic challenges for process designing. Int J Mol Sci 16:2068520703. https://doi.org/10.3390/ijms160920685

Kang H, Jung J-H, Kim S-W, Ahn H-K, Jung K-H (2014) Anaerobic batch multiple degradation rates of dairy cow manure. In: Proceedings of the 25 th annual meeting of waste resource circulation society 2014 . The 25 th annual conference of Japan society of material cycles and waste management, pp 550-551. https:// www.jstage.jst.go.jp/article/jsmcwm/25/0/25_550/_pdf/-char/en

Karim K, Klasson KT, Drescher SR, Ridenour W, Borole AP, Al-Dahhan MH (2007) Mesophilic digestion kinetics of manure slurry. Appl Biochem Biotechnol 142:231-242. https://doi.org/10.1007/ s12010-007-0025-4

Kasana RC, Gulati A (2011) Cellulases from psychrophilic microorganisms: a review. J Basic Microbiol 51:572-579. https://doi. org/10.1002/jobm.201000385

Llabrés-Luengo P, Mata-Alvarez J (1987) Kinetic study of the anaerobic digestion of straw-pig manure mixtures. Biomass 14:129-142. https://doi.org/10.1016/0144-4565(87)90015-1

Lynd LR, Laser MS, Bransby D, Dale BE, Davison B, Hamilton R et al (2008) How biotech can transform biofuels. Nat Biotechnol 26:169-172. https://doi.org/10.1038/nbt0208-169

Mao C, Feng Y, Wang X, Ren G (2015) Review on research achievements of biogas from anaerobic digestion. Renew Sustain Energy Rev 45:540-555. https://doi.org/10.1016/j.rser.2015.02.032

Massé DI, Masse L, Xia Y, Gilbert Y (2010) Potential of low-temperature anaerobic digestion to address current environmental concerns on swine production1. J Anim Sci 88:E112-E120. https:// doi.org/10.2527/jas.2009-2432

Møller HB, Sommer SG, Ahring BK (2004) Methane productivity of manure, straw and solid fractions of manure. Biomass Bioenergy 26:485-495. https://doi.org/10.1016/j.biombioe.2003.08.008

Neves L, Gonçalo E, Oliveira R, Alves MM (2008) Influence of composition on the biomethanation potential of restaurant waste at mesophilic temperatures. Waste Manag 28:965-972. https://doi. org/10.1016/j.wasman.2007.03.031

Nielfa A, Cano R, Fdz-Polanco M (2015) Theoretical methane production generated by the co-digestion of organic fraction municipal solid waste and biological sludge. Biotechnol Rep 5:14-21. https ://doi.org/10.1016/j.btre.2014.10.005

Nozhevnikova AN, Simankova MV, Parshina SN, Kotsyurbenko OR (2001) Temperature characteristics of methanogenic archaea and acetogenic bacteria isolated from cold environments. Water Sci Technol 44(8):41-48

Paul S, Dutta A (2018) Challenges and opportunities of lignocellulosic biomass for anaerobic digestion. Resour Conserv Recycl 130:164-174. https://doi.org/10.1016/j.resconrec.2017.12.005 
Pella E, Colombo B (1972) Improved instrumental determination of oxygen in organic compounds by pyrolysis-gas chromatography. Anal Chem 44:1563-1571. https://doi.org/10.1021/ac60317a023

Pella E, Colombo B (1973) Study of carbon, hydrogen and nitrogen determination by combustion-gas chromatography. Mikrochim Acta 61:697-719. https://doi.org/10.1007/bf01218130

Pohl M, Heeg K, Mumme J (2013) Anaerobic digestion of wheat straw-performance of continuous solid-state digestion. Bioresour Technol 146:408-415. https://doi.org/10.1016/j.biort ech.2013.07.101

Qamaruz-Zaman N, Milke MW (2012) VFA and ammonia from residential food waste as indicators of odor potential. Waste Manag 32:2426-2430. https://doi.org/10.1016/j.wasman.2012.06.023

Rittmann BE, McCarty PL (2001) Environmental biotechnology: principles and applications. McGraw-Hill, Boston

Rolfe MD, Rice CJ, Lucchini S, Pin C, Thompson A, Cameron ADS, Hinton JCD (2012) Lag phase is a distinct growth phase that prepares bacteria for exponential growth and involves transient metal accumulation. J Bacteriol 194(3):686-701. https://doi. org/10.1128/jb.06112-11

Saady NMC, Massé DI (2013) Psychrophilic anaerobic digestion of lignocellulosic biomass: a characterization study. Bioresour Technol 142:663-671. https://doi.org/10.1016/j.biortech.2013.05.089

Saady NMC, Massé D (2015) Impact of organic loading rate on psychrophilic anaerobic digestion of solid dairy manure. Energies 8:1990-2007. https://doi.org/10.3390/en8031990

Safley LM Jr, Westerman PW (1994) Low-temperature digestion of dairy and swine manure. Bioresour Technol 47:165-171. https:// doi.org/10.1016/0960-8524(94)90116-3

Singh R, Jain MK, Tauro P (1982) Rate of anaerobic digestion of cattle waste. Agric Wastes 4:267-272. https://doi.org/10.1016/01414607(82)90002-6
Torres-Castillo R, Llabres-Luengo P, Mata-Alvarez J (1995) Temperature effect on anaerobic digestion of straw in a one phase system at different inoculum concentration. Agric Ecosyst Environ 54:55-66

van Lier JB, Rebac S, Lettinga G (1997) High-rate anaerobic wastewater treatment under psychrophilic and thermophilic conditions. Water Sci Technol 35(10):199-206. https://doi.org/10.1016/S0273 -1223(97)00202-3

von Stockar U, Maskow T, Liu J, Marison IW, Patino R (2006) Thermodynamics of microbial growth and metabolism: an analysis of the current situation. J Biotechnol 121(4):517-533. https://doi. org/10.1016/j.jbiotec.2005.08.012

Wilkie AC, Riedesel KJ, Owens JM (2000) Stillage characterization and anaerobic treatment of ethanol stillage from conventional and cellulosic feedstocks. Biomass Bioenergy 19:63-102

Yue Z, Teater C, MacLellan J, Liu Y, Liao W (2011) Development of a new bioethanol feedstock - anaerobically digested fiber from confined dairy operations using different digestion configurations. Biomass Bioenergy 35:1946-1953. https://doi.org/10.1016/j. biombioe.2011.01.035

Zeeman G, Sutter K, Vens T, Koster M, Wellinger A (1988) Psychrophilic digestion of dairy cattle and pig manure: start-up procedures of batch, fed-batch and CSTR-type digesters. Biol Wastes 26(1):15-31

Publisher's Note Springer Nature remains neutral with regard to jurisdictional claims in published maps and institutional affiliations. 